\title{
A controlled study of temporal lobe structure volumes and P300 responses in schizophrenic patients with persistent auditory hallucinations
}

Citation for published version (APA):

Havermans, R., Honig, A., Vuurman, E. F. P. M., Krabbendam, L., Wilmink, J., Lamers, T. H., Verheecke, C. J., Jolles, J., Romme, M. A. J., \& van Praag, H. M. (1999). A controlled study of temporal lobe structure volumes and $\mathrm{P} 300$ responses in schizophrenic patients with persistent auditory hallucinations. Schizophrenia Research, 38(2-3), 151-158. https://doi.org/10.1016/S0920-9964(99)00006-7

Document status and date:

Published: 01/01/1999

DOI:

10.1016/S0920-9964(99)00006-7

Document Version:

Publisher's PDF, also known as Version of record

Please check the document version of this publication:

- A submitted manuscript is the version of the article upon submission and before peer-review. There can be important differences between the submitted version and the official published version of record.

People interested in the research are advised to contact the author for the final version of the publication, or visit the DOI to the publisher's website.

- The final author version and the galley proof are versions of the publication after peer review.

- The final published version features the final layout of the paper including the volume, issue and page numbers.

Link to publication

\footnotetext{
General rights rights.

- You may freely distribute the URL identifying the publication in the public portal. please follow below link for the End User Agreement:

www.umlib.nl/taverne-license

Take down policy

If you believe that this document breaches copyright please contact us at:

repository@maastrichtuniversity.nl

providing details and we will investigate your claim.
}

Copyright and moral rights for the publications made accessible in the public portal are retained by the authors and/or other copyright owners and it is a condition of accessing publications that users recognise and abide by the legal requirements associated with these

- Users may download and print one copy of any publication from the public portal for the purpose of private study or research.

- You may not further distribute the material or use it for any profit-making activity or commercial gain

If the publication is distributed under the terms of Article $25 \mathrm{fa}$ of the Dutch Copyright Act, indicated by the "Taverne" license above, 


\title{
A controlled study of temporal lobe structure volumes and P300 responses in schizophrenic patients with persistent auditory hallucinations
}

\author{
R. Havermans *, A. Honig, E.F.P.M. Vuurman, L. Krabbendam, J. Wilmink, \\ Th. Lamers, C.J. Verheecke, J. Jolles, M.A.J. Romme, H.M. van Praag \\ Department of Psychiatry and Neuropsychology and the Department of Radiology, Maastricht University, P.O. Box 616, \\ 6200 MD Maastricht, The Netherlands
}

Received 12 December 1998; accepted 22 December 1998

\begin{abstract}
Recent studies of cerebral pathology in patients with schizophrenia have focused on symptomatological and electrophysiological correlates of reduced temporal lobe structure volumes. Volume deficits of the left superior temporal gyrus have been correlated with auditory hallucinations as well as to left-sided P300 amplitude reduction. However, caution is needed to interpret correlational data as evidence of a specific relationship. Therefore, a controlled study was undertaken on schizophrenic patients with and without auditory hallucinations.

MRI-defined volumes of the left superior temporal gyrus and other temporal lobe structures were quantified from 3-mm coronal slices in 15 schizophrenic patients with chronic auditory hallucinations (hallucinators), 15 schizophrenic patients without auditory hallucinations (nonhallucinators) and 17 healthy controls. In all subjects a simple oddball paradigm was used to elicit P300 responses at temporal and centro-parietal electrode sites.

No evidence was found for volume reductions of temporal lobe structures in the combined patient group compared with controls, or in the hallucinators compared with the nonhallucinators. The patients did show left P300 amplitude reduction compared with controls, particularly in the hallucinator group. Correlations between volumes of left temporal lobe structures and left P300 amplitudes were low and not significant.

The results of the present study do not indicate that auditory hallucinations and associated abnormal electrophysiological activity are the consequence of atrophy of localized temporal lobe structures. However, replication in a larger sample of subjects is needed before firm conclusions can be drawn. (C) 1999 Elsevier Science B.V. All rights reserved.
\end{abstract}

Keywords: Schizophrenia; Auditory hallucinations; Temporal lobe; Magnetic resonance imaging; Event-related potentials

\footnotetext{
* Corresponding author. Mailing address: Maastricht University, Faculty of Medicine, Department of Psychiatry and Neurophysiology, P.O. Box 616, 6200 MD Maastricht, The Netherlands.
} 


\section{Introduction}

Recent quantitative magnetic resonance imaging (MRI) studies of cerebral pathology in patients with schizophrenia have focused on possible volume reductions of temporal lobe structures. In a recent review, Chua and Mckenna (1995) concluded that about half of the studies demonstrated reduced volumes of temporal lobe structures, predominantly left-sided, while in the other half of the studies no significant volume deficits were found. These divergent results are possibly related to the syndromal heterogeneity of schizophrenia. According to the conceptual framework of functional psychopathology (Van Praag, 1993, 1997), biological abnormalities are more likely to be linked with symptoms (and underlying psychological dysfunctions) than with syndromes. In recent years, several studies have been conducted on the association between structural abnormalities in the temporal lobe and specific symptoms (Barta et al., 1990; Shenton et al., 1992; Menon et al., 1995). The present study focuses on the association between auditory hallucinations and volume deficits of temporal lobe structures. Barta et al. (1990) reported that volume deficits of the anterior part of the left superior temporal gyrus (STG) were strongly and selectively correlated with severity of auditory hallucinations. This finding is interesting, because the left STG forms the core of what is traditionally known as Wernicke's area, a region that is thought to play an important role in the processing of speech and language functions (Penfield and Perot, 1963; Tranel, 1992). Electrophysiological studies on event-related potentials (ERP) in schizophrenia have shown that volume reduction of the left STG is correlated with P300 amplitude reduction at left temporal sites (McCarley et al., 1993; Egan et al., 1994). Together, these findings suggest that in patients with schizophrenia, volume reduction of the left STG is linked to auditory hallucinations, as well as to electrophysiological disturbances. Caution, however, is needed to interpret correlational data as evidence of a specific relationship. We therefore decided to carry out a controlled study with two groups of patients with schizophrenia, that differed only in the presence of auditory hallucinations.
The general goal of the study was to further explore whether schizophrenia and auditory hallucinations are related to structural and electrophysiological abnormalities of the temporal regions. The specific goal of the study was to test the hypothesis that auditory hallucinations in schizophrenia are related to volume reductions of the left anterior STG.

\section{Methods}

\subsection{Subjects}

Three groups of subjects were studied. The index group consisted of 15 right-handed schizophrenic patients, seven males and eight females, with chronic auditory verbal hallucinations (the hallucinators). Chronic was defined as persistent hallucinations present for at least the past 6 months. This patient group had a mean age of 37.6 years $(\mathrm{SD}=7.7$, range $=20.9-52.4)$ and a mean height of $172.6 \mathrm{~cm} \quad(\mathrm{SD}=4.9$, range $=$ 164-181). Their mean chlorpromazine equivalent daily dose of neuroleptic medication was $316 \mathrm{mg} /$ day $(\mathrm{SD}=251$, range $=0-875)$ and they had a mean total score of $42.9(\mathrm{SD}=11.0$, range $=$ 28-63) on the Brief Psychiatric Rating Scale (BPRS) (Overall and Gorham, 1962). A second group of patients consisted of 15 right-handed schizophrenic patients, eight males and seven females, who had never experienced auditory hallucinations (the nonhallucinators). This patient group had a mean age of 35.0 years $(\mathrm{SD}=9.2$, range $=23.0-56.7)$ and a mean height of 172.4 $(\mathrm{SD}=7.0$, range $=162-186)$. They used a mean chlorpromazine equivalent daily dose of $291 \mathrm{mg} /$ day $(\mathrm{SD}=133$, range $=0-500)$ and had a mean total BPRS score of $45.9(\mathrm{SD}=9.8$, range $=$ 31-63). All patients were outpatients, recruited from the local Community Psychiatric Service and from the two catchment area psychiatric hospitals. The DSM-IV diagnoses were reached by consensus of the referring psychiatrist and the research team, using the Composite International Diagnostic Interview (CIDI) (Robins et al., 1988).

A control group of 17 right-handed healthy volunteers was recruited through local newspaper 
advertisements. Mean age was 37.2 years $(\mathrm{SD}=$ 9.1, range $=21.2-53.2$ ). Controls (eight males and nine females) had no history of psychiatric diseases or history of use of psychotropic medication. The absence of psychiatric symptomatology was checked by applying the CIDI.

Exclusion criteria for all three groups were any history of CNS illness, head injury that had caused unconsciousness for more than $1 \mathrm{~h}$, alcohol or drug abuse over the past 12 months, and loss of $25 \%$ or more of original body weight over the past 12 months. Written informed consent was obtained from all subjects.

There were no statistically significant differences between the three groups in height, age and sex ratio. Also, between the two patients groups there were no significant differences in BPRS total score and mean dosage of neuroleptic medication.

\subsection{Magnetic resonance imaging}

Images were acquired on a 1.5 Tesla MRI scanner (Philips ACS). The scanning protocol consisted of a coronal inversion recovery $\mathrm{T} 1$ weighted sequence, perpendicular to the long axis of the hippocampus (TR/TI/TE 2107/300/18 ms, matrix $256 \times 179$, FOV $23 \mathrm{~cm}$, NEX 2, turbofactor 3, $3-\mathrm{mm}$ thick contiguous slices, acquisition time 6:53 min). The images were transferred to a standalone SUN workstation and examined with a semiautomated Gyroview software package containing a manual contouring function using a mouse. After outlining the regions of interest (ROIs) in contiguous slices, volumes were calculated by multiplying the areas by the slice thickness and adding contiguous slices.

ROIs were the amygdala, hippocampus, superior temporal gyrus (STG), parahippocampal gyrus (PHG) and the temporal lobe. Anatomic guidelines for delineation of the ROIs were established using whole brain sections and coronal serial sections (provided from the Laboratory of Pathological Anatomy of the Academic Hospital Maastricht), neuroanatomy atlases (Duvernoy, 1988; Nieuwenhuys et al., 1988) and previously published guidelines on MRI volume measurements of temporal lobe structures (Watson et al., 1992; Bartzokis et al., 1993). The landmarks used to define the anterior and posterior extent of all regions were taken from Shenton et al. (1992). In order to make comparison with the study of Barta et al. (1990) possible, the left anterior STG was examined separately. This area was defined as the added volumes of the first three slices of the left STG. Discrimination of the amygdala and hippocampus was difficult in some slices. Therefore, we decided to divide the amygdala-hippocampus complex into the amygdala-anterior hippocampus and the posterior hippocampus. The most anterior slice of the latter was defined as the slice showing the largest diameter of the mammillary bodies. The subiculum was included in the measurement of the hippocampus. The temporal lobe included the anterior temporal pole. Due to limitations of spatial resolution separate measurement of white matter and gray matter in the STG and the PHG was not possible. All regions of all subjects were measured by the same rater, under blind conditions. To determine reliability of the measurements, all regions in a subset of eight subjects were remeasured after at least 3 weeks by the same rater and intraclass correlation coefficients were calculated. Reliability of measurement of left and right posterior hippocampus on both sides were considered insufficient $(r<0.75)$, and volumes of these structures were excluded from further analysis. The intraclass correlation coefficients of the remaining structures ranged from 0.85 to 0.98 (mean 0.90), indicating excellent test-retest reliability.

\subsection{Event-related potentials}

A simple auditory oddball paradigm was used to elicit P300 responses. Targets were high tones ( $2000 \mathrm{~Hz}, 80 \mathrm{~dB}, 100 \mathrm{~ms}$ ) pseudorandomly distributed within a stream of nontarget low tones $(1000 \mathrm{~Hz}, 80 \mathrm{~dB}, 100 \mathrm{~ms})$. The total number of stimulus presentations depended on the number of artefact free target trials which was set at 32 . The interstimulus time was $1000 \mathrm{~ms}$ and target and nontarget stimuli appeared with a probability of 15 and $85 \%$, respectively. Subjects were requested to press a hand-held button when they detected a target stimulus. They were instructed to respond without any emphasis on a speeded response, 
limiting the possible contamination of the P300 with motor potentials. Single trial, $800 \mathrm{~ms}$ EEG epochs, starting $100 \mathrm{~ms}$ before stimulus onset were recorded and stored from 22 electrode sites using linked ears as a reference. The sample rate was $67 \mathrm{~Hz}$, bandpass was between $0.15 \mathrm{~Hz}(36 \mathrm{~dB} /$ octave) and $70 \mathrm{~Hz}$ (12 dB/octave). Eye-movements were recorded on a separate channel and trials with blinks or EOG $>50 \mu \mathrm{V}$ were discarded. Similar to the study of McCarley et al. (1993), apart from the standard $10-20$ positions the following sites were also included: TCP1 placed at the intersection of C3-T5 and P3-T3; and CP1, placed at the midpoint of the diagonal formed by $\mathrm{Cz}-\mathrm{P} 3$. Homologous sites were used on the contralateral side. Peak P300 amplitudes were measured from temporal and adjacent centro-parietal electrode sites: T3/T4, T5/T6, TCP1/TCP2, C3/C4, $\mathrm{P} 3 / \mathrm{P} 4$ and $\mathrm{CP} 1 / \mathrm{CP} 2$.

\subsection{Statistical analysis}

Data were analysed with two way univariate analyses with 'group' as between subject-factor and 'hemisphere' as within subject-factor. In volumetric analyses, height was used as a covariate, to control for differences in brain size. Subsequent one way ANOVAs with a priori contrasts (all patients vs controls; hallucinators vs nonhallucinators) were conducted in cases of significant group effects or group-by-hemisphere interactions. A similar analysis was conducted on group mean volumes of the anterior part of the left STG. Pearson correlations were used to assess the predicted relationship between (absolute) volumes of selected left ROIs and left P300 amplitudes in the combined patient group. In light of the modest sample size and the explorative character of the study, alpha was set at 0.05 for all tests (two-tailed).

\section{Results}

Two way analysis of variance on ROI volumes showed no effect of group or group-by-hemisphere interaction. An effect of hemisphere was demonstrated only for STG volumes (left $<$ right). The hypothesis-driven comparison of mean volumes of the anterior part of the left STG revealed no significant differences between patients and controls $(p=0.43)$, and between hallucinators and nonhallucinators $(p=0.11)$ (Table 1$)$.

Two way analysis of variance on left and right P300 amplitudes revealed group effects at the central electrode sites $(\mathrm{CP} 1 / \mathrm{CP} 2$ and $\mathrm{C} 3 / \mathrm{C} 4)$. Effects for hemisphere were found at $\mathrm{C} 3 / \mathrm{C} 4$ and P3/P4 (left $<$ right). Significant group-by-hemisphere interaction was found at $\mathrm{CP} 1 / \mathrm{CP} 2$ and TCP1/TCP2 (Table 2). Follow-up univariate F tests with a priori contrasts revealed P300 amplitude reductions in the combined patient group compared with healthy controls at TCP1 $(p=$ $0.006), \mathrm{C} 3(p=0.007)$ and CP1 $(p<0.001)$, and in the hallucinators compared with the nonhallucinators at $\mathrm{C} 3(p=0.05)$.

ERP waveforms at these sites are shown in Fig. 1. Correlations between left ROI volumes and left P300 amplitudes in the combined patient group were low and not significant.

\section{Discussion}

We studied temporal lobe structure volumes and P300 amplitudes in a well diagnosed group of schizophrenic patients with chronic auditory hallucinations in comparison with a group of schizophrenic patients without auditory hallucinations and a group of healthy controls.

Contrary to the initial hypothesis, we did not find that the symptom of auditory hallucinations in schizophrenia is related to a volume reduction of the anterior part of the left STG. This finding is in contrast with a previous study (Barta et al., 1990). There are important differences between this study and the present one in subject selection, symptom definition, and methods of analysis. Firstly, we studied groups of male and female patients, while in the above-mentioned study only male patients were included. It has been reported that brain abnormalities are more prominent in males with schizophrenia (Nopoulos et al., 1997). The number of subjects was too modest to make meaningful comparisons of gender. Secondly, we focused on chronic auditory hallucinations instead of a presumably more state-dependent severity 
Table 1

MRI measures in patients with and without auditory hallucinations and healthy controls

\begin{tabular}{|c|c|c|c|c|c|c|c|c|c|c|c|c|c|}
\hline \multirow[b]{3}{*}{ Brain region } & & \multicolumn{2}{|c|}{$\begin{array}{l}\text { Group } 1 \\
\text { Hallucinators } \\
(n=15)\end{array}$} & \multicolumn{2}{|c|}{$\begin{array}{l}\text { Group } 2 \\
\text { Nonhallucinators } \\
(n=15)\end{array}$} & \multicolumn{2}{|c|}{$\begin{array}{l}\text { Group } 3 \\
\text { Controls } \\
(n=17)\end{array}$} & \multicolumn{6}{|c|}{$\begin{array}{l}\text { Two way } \\
\text { ANOVA }\end{array}$} \\
\hline & & \multirow[b]{2}{*}{ Mean } & \multirow[b]{2}{*}{ SD } & \multirow[b]{2}{*}{ Mean } & \multirow[b]{2}{*}{ SD } & \multirow[b]{2}{*}{ Mean } & \multirow[b]{2}{*}{ SD } & \multicolumn{2}{|c|}{$\begin{array}{l}\text { Group } \\
(\mathrm{df}=2,44)\end{array}$} & \multicolumn{2}{|c|}{$\begin{array}{l}\text { Hemisphere } \\
(\mathrm{df}=1,44)\end{array}$} & \multicolumn{2}{|c|}{$\begin{array}{l}\text { Interaction } \\
(\mathrm{df}=2,44)\end{array}$} \\
\hline & & & & & & & & $\mathrm{F}$ & $p$ & $\mathrm{~F}$ & $p$ & $\mathrm{~F}$ & $p$ \\
\hline \multirow[t]{2}{*}{ Superior temporal gyrus } & $\mathrm{L}$ & 15.96 & 2.26 & 14.94 & 2.14 & 15.55 & 1.62 & \multirow{2}{*}{2.43} & \multirow{2}{*}{0.10} & \multirow{2}{*}{7.87} & \multirow{2}{*}{0.007} & \multirow{2}{*}{0.24} & \multirow{2}{*}{0.79} \\
\hline & $\mathrm{R}$ & 17.17 & 2.03 & 15.67 & 1.73 & 16.30 & 1.69 & & & & & & \\
\hline \multirow[t]{2}{*}{ Parahippocampal gyrus } & $\mathrm{L}$ & 6.02 & 0.71 & 5.77 & 0.95 & 5.52 & 0.48 & \multirow{2}{*}{2.93} & \multirow{2}{*}{0.06} & \multirow{2}{*}{3.39} & \multirow{2}{*}{0.07} & \multirow{2}{*}{0.96} & \multirow{2}{*}{0.39} \\
\hline & $\mathrm{R}$ & 6.35 & 0.63 & 5.78 & 0.94 & 5.69 & 0.72 & & & & & & \\
\hline \multirow{2}{*}{$\begin{array}{l}\text { Anterior amygdala- } \\
\text { hippocampus }\end{array}$} & $\mathrm{L}$ & 2.16 & 0.45 & 2.01 & 0.55 & 1.96 & 0.42 & \multirow{2}{*}{1.92} & \multirow{2}{*}{0.16} & \multirow{2}{*}{0.65} & \multirow{2}{*}{0.43} & \multirow{2}{*}{0.55} & \multirow{2}{*}{0.58} \\
\hline & $\mathrm{R}$ & 2.35 & 0.75 & 2.02 & 0.61 & 1.95 & 0.42 & & & & & & \\
\hline \multirow[t]{2}{*}{ Temporal lobe } & $\mathrm{L}$ & 80.45 & 8.21 & 77.32 & 10.77 & 77.65 & 6.01 & 096 & 039 & O 70 & 0.41 & 020 & 080 \\
\hline & $\mathrm{R}$ & 81.62 & 7.48 & 77.32 & 8.95 & 78.73 & 8.24 & 0.96 & 0.39 & 0.70 & 0.41 & 0.22 & 0.80 \\
\hline $\begin{array}{l}\text { Left anterior superior } \\
\text { temporal gyrus }\end{array}$ & & 2.42 & 0.41 & 2.20 & 0.37 & 2.22 & 0.32 & - & - & - & - & - & - \\
\hline
\end{tabular}

Table 2

P300 amplitudes $(\mu \mathrm{V})$ in patients with and without auditory hallucinations and healthy controls

\begin{tabular}{|c|c|c|c|c|c|c|c|c|c|c|c|c|}
\hline \multirow[b]{3}{*}{ Electrode site } & \multicolumn{2}{|c|}{$\begin{array}{l}\text { Group } 1 \\
\text { Hallucinators } \\
(n=15)\end{array}$} & \multicolumn{2}{|c|}{$\begin{array}{l}\text { Group } 2 \\
\text { Nonhallucinators } \\
(n=15)\end{array}$} & \multicolumn{2}{|c|}{$\begin{array}{l}\text { Group } 3 \\
\text { Controls } \\
(n=17)\end{array}$} & \multicolumn{6}{|c|}{$\begin{array}{l}\text { Two way } \\
\text { ANOVA }\end{array}$} \\
\hline & \multirow[b]{2}{*}{ Mean } & \multirow[b]{2}{*}{ SD } & \multirow[b]{2}{*}{ Mean } & \multirow[b]{2}{*}{ SD } & \multirow[b]{2}{*}{ Mean } & \multirow[b]{2}{*}{ SD } & \multicolumn{2}{|c|}{$\begin{array}{l}\text { Group } \\
(\mathrm{df}=2,44)\end{array}$} & \multicolumn{2}{|c|}{$\begin{array}{l}\text { Hemisphere } \\
(\mathrm{df}=1,44)\end{array}$} & \multicolumn{2}{|c|}{$\begin{array}{l}\text { Interaction } \\
(\mathrm{df}=2,44)\end{array}$} \\
\hline & & & & & & & $\mathrm{F}$ & $p$ & $\mathrm{~F}$ & $p$ & $\mathrm{~F}$ & $p$ \\
\hline $\mathrm{T} 3$ & 6.49 & 2.90 & 7.41 & 4.53 & 7.71 & 3.65 & \multirow{2}{*}{1.12} & \multirow{2}{*}{0.33} & \multirow{2}{*}{0.57} & \multirow{2}{*}{0.45} & \multirow{2}{*}{0.45} & \multirow{2}{*}{0.64} \\
\hline $\mathrm{T} 4$ & 6.28 & 2.37 & 8.03 & 3.49 & 8.25 & 4.35 & & & & & & \\
\hline T5 & 9.32 & 4.21 & 10.87 & 5.23 & 11.35 & 3.95 & \multirow{2}{*}{1.67} & \multirow{2}{*}{0.20} & \multirow{2}{*}{0.52} & \multirow{2}{*}{0.47} & \multirow{2}{*}{1.58} & \multirow{2}{*}{0.22} \\
\hline T6 & 10.23 & 4.87 & 13.62 & 8.30 & 10.40 & 5.37 & & & & & & \\
\hline TCP1 & 7.41 & 3.70 & 9.87 & 5.50 & 13.16 & 5.57 & \multirow{2}{*}{3.05} & \multirow{2}{*}{0.06} & \multirow{2}{*}{2.18} & \multirow{2}{*}{0.15} & \multirow{2}{*}{5.73} & \multirow{2}{*}{0.006} \\
\hline TCP2 & 10.04 & 3.67 & 11.32 & 4.89 & 11.91 & 6.49 & & & & & & \\
\hline $\mathrm{C} 3$ & 6.48 & 3.69 & 10.27 & 6.77 & 12.86 & 5.00 & \multirow{2}{*}{3.14} & \multirow{2}{*}{0.05} & \multirow{2}{*}{19.96} & $<0001$ & 258 & 009 \\
\hline $\mathrm{C} 4$ & 10.84 & 3.91 & 12.51 & 7.45 & 13.88 & 7.78 & & & & $<0.001$ & 2.58 & 0.09 \\
\hline P3 & 11.02 & 5.33 & 14.10 & 7.40 & 14.25 & 6.69 & & & & & & \\
\hline P4 & 14.60 & 8.29 & 17.79 & 9.72 & 19.22 & 8.58 & 1.58 & 0.22 & 11.23 & 0.002 & 0.35 & 0.70 \\
\hline $\mathrm{CP} 1$ & 9.20 & 3.64 & 11.83 & 6.70 & 18.53 & 4.90 & 570 & & & & 506 & \\
\hline $\mathrm{CP} 2$ & 12.27 & 4.84 & 13.51 & 8.45 & 16.38 & 8.71 & 5.10 & 0.000 & $1.4 /$ & 0.23 & 5.00 & 0.01 \\
\hline
\end{tabular}

score for auditory hallucinations (Barta et al., 1990). Thirdly, the associations reported in this study were based on correlation analyses while we compared two groups of patients that differed only in the specific symptom assessed. Fourthly, there are differences in the way that variations in brain 


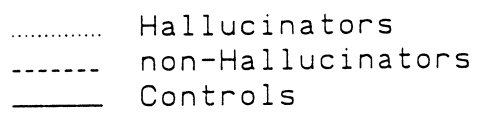

non-target trials
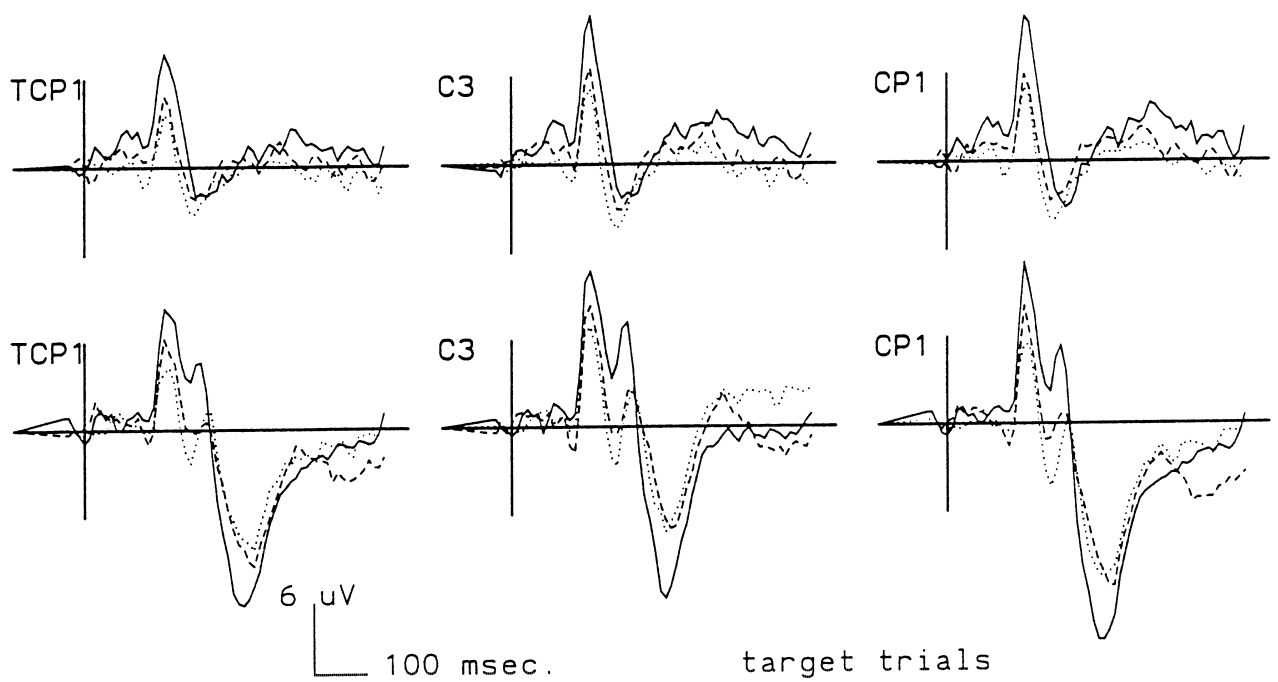

Fig. 1. Average ERP responses on targets and nontargets for patients with and without auditory hallucinations and healthy controls.

size were controlled for. Volumes were corrected for differences in whole brain volume (Barta et al., 1990), while we corrected for differences in brain size by using height as a covariate. As suggested by Arndt et al. (1991), height is a reasonable measure for premorbid brain volume, as it is closely correlated with brain size in normal subjects and is unlikely to be influenced by pathological processes affecting the brain. Possibly, our nonreplication is due to these methodological differences. It can be questioned whether lack of power is a main reason for the nonsignificant findings. However, there were not even trends in the hypothesized directions and the largest mean volume of the left anterior STG was found in the hallucinator group. Given that there are more negative studies (DeLisi et al., 1994; Zipursky et al., 1994), it seems fair to conclude that replication in a larger sample size is necessary before firm conclusions can be drawn.

In the explorative part of the study we found no evidence for volumetric deficits of temporal lobe structures related to schizophrenia or to auditory hallucinations. The former finding is in contrast with some studies (e.g. Bogerts et al., 1990;
Shenton et al., 1992), but in line with others (e.g. Young et al., 1991; Kulynych et al., 1996). Differences in subject selection, delineation of ROIs and image acquisition and the potential for Type I and Type II errors may have contributed to the disparate results. One point of consideration with our study was that we were not able to separate gray matter from white matter, due to limitations of spatial resolution. It has been reported that in schizophrenia, gray matter deficits are more pronounced than white matter deficits (Zipursky et al., 1992, 1994). These reported deficits, however, were not restricted to temporal lobe structures but were more widespread. This leaves unsettled the issue whether localized temporal lobe volume deficits in schizophrenia exist.

Our finding of P300 amplitude reductions at left centro-parietal sites in patients with schizophrenia compared with controls has to be interpreted with caution, because we did not correct for multiple comparisons. This finding, however, is consistent with earlier reports (Morstyn et al., 1983; Faux et al., 1988; for a recent review see Salisbury et al., 1998). This left P300 asymmetry was most pronounced in the hallucinator group. Neither in the 
hallucinators nor in the nonhallucinators, were volumes of the left ROIs associated with any of the selected left-sided P300 amplitudes. The previously reported association between left STG volume and P300 amplitude at T3 may be present only in a subgroup of schizophrenic patients with reduced left STG volume (McCarley et al., 1993). It is important to realize that although the STG plays an important role in the generation of the P300 waveform, it is assumed that other brain regions including frontal and parietal areas also make a substantial contribution (Halgren et al., 1986; Knight et al., 1989; Wood and McCarthey, 1985).

In conclusion, taking into account some methodological limitations and the limited sample size, the results of the present study do not indicate that auditory hallucinations and associated abnormal electrophysiological activity are the consequence of atrophy of the STG and other localized temporal lobe structures. In line with the concept of disordered functional connectivity in schizophrenia (Weinberger et al., 1992; McGuire and Frith, 1996), McGuire et al. (1995) have hypothesized that the generation of auditory hallucinations is associated with aberrant connectivity in a network of cortical language areas. Future studies, incorporating a larger sample size and using structural as well as functional imaging techniques, are needed to further test this hypothesis and gain further insight into the neurobiological basis of auditory hallucinations.

\section{Acknowledgments}

This study was supported by a grant from the Academic Hospital Maastricht. We thank P. Hofman for his kind advice regarding the MRI image acquisition, D. Corstens for organizing subject recruitment and J. van Os for his comments on an earlier version of this paper.

\section{References}

Arndt, S., Cohen, G., Alliger, R.J., Swayze, V.W., Andreasen, N.C., 1991. Problems with ratio and proportion measures of imaged cerebral structures. Psychiatry Res. 40, 79-89.
Barta, P.E., Pearlson, G.D., Powers, R.E., Richards, S.S., Tune, L.E., 1990. Auditory hallucinations and smaller superior temporal gyral volume in schizophrenia. Am. J. Psychiatry 147, 1457-1462.

Bartzokis, G., Mintz, J., Marx, P., Osborn, D., Gutkind, D., Chiang, F., Phelan, K., Marder, S.R., 1993. Reliability of in vivo volume measures of hippocampus and other brain structures using MRI. Magnet. Reson. Imaging 11, 993-1006.

Bogerts, B., Ashtari, M., Degreef, G., Alvir, J.Ma.J., Bilder, R.M., Liebermann, J.A., 1990. Reduced temporal limbic structure volumes on magnetic resonance images in first episode schizophrenia. Psychiatry Res.: Neuroimaging 35, 1-13.

Chua, S.E., McKenna, P.J., 1995. Schizophrenia - a brain disease? A critical review of structural and functional cerebral abnormality in the disorder. Br. J. Psychiatry 166, 563-582.

DeLisi, L.E., Hoff, A.L., Neale, C., Kushner, M., 1994. Asymmetries in the superior temporal lobe in male and female first-episode schizophrenic patients: measures of the planum temporale and superior temporal gyrus by MRI. Schizophr. Res. 12, 19-28.

Duvernoy, H.M. (1988) The Human Hippocampus: An Atlas of Applied Anatomy. J.F. Bergmann, Munchen.

Egan, M.F., Duncan, C.C., Suddath, R.L., Kirch, D.G., Mirsky, A.F., Wyatt, R.J., 1994. Event-related potential abnormalities correlate with structural brain alterations and clinical features in patients with chronic schizophrenia. Schizophr. Res. 11, 259-271.

Faux, S.F., Torello, M., McCarley, R.W., Shenton, M.E., Duffy, F.H., 1988. P300 in schizophrenia: confirmation and statistical validation of temporal region deficit in P300 topography. Biol. Psychiatry 23, 776-790.

Halgren, E., Stapleton, J.M., Smith, M., Altafullah, I., 1986. Generators of the human scalp P3. In: Gracco, O., Bodis Wollner, J. (Eds.), Evoked Potentials. Alan Liss, New York, pp. 269-284.

Knight, R.T., Scabini, D., Woods, D.L., Clayworth, C.C., 1989. Contributions of temporal-parietal junction to the human auditory P3. Brain Res. 502, 109-116.

Kulynych, J.J., Vladar, K., Jones, D.W., Weinberger, D.R., 1996. Superior temporal gyrus volume in schizophrenia: a study using MRI morphometry assisted by surface rendering. Am. J. Psychiatry 153, 50-56.

McCarley, R.W., Shenton, M.E., O’Donnell, B.F., Faux, S.F., Kikinis, R., Nestor, P.G., Jolesz, F.A., 1993. Auditory P300 abnormalities and left posterior superior temporal gyrus volume reduction in schizophrenia. Arch. Gen. Psychiatry 50, 190-197.

McGuire, P.K., Frith, C.D., 1996. Disordered functional connectivity in schizophrenia. Psychol. Med. 26, 663-667.

McGuire, P.K., Silbersweig, D.A., Wright, I., Murray, R.M., David, A.S., Frackowiak, R.S.J., Frith, C.D., 1995. Abnormal monitoring of inner speech: a physiological basis for auditory hallucinations. The Lancet 346, 596-600.

Menon, R.R., Barta, P.E., Aylward, E.H., Richards, S.S., Vaughn, D.D., Tien, A.Y., Harris, G.J., Pearlson, G.D., 1995. Posterior superior temporal gyrus in schizophrenia: 
grey matter changes and clinical correlates. Schizophr. Res. $16,127-135$.

Morstyn, R., Duffy, F.H., McCarley, R.W., 1983. Altered P300 topography in schizophrenia. Arch. Gen. Psychiatry 40, 729-734.

Nieuwenhuys, R., Voogd, J., van Huijzen, C., 1988. The Human Central Nervous System: A Synopsis and Atlas. Springer, New York.

Nopoulos, P., Flaum, M., Andreasen, N.C., 1997. Sex differences in brain morphology in schizophrenia. Am. J. Psychiatry 154, 1648-1654.

Overall, J.E., Gorham, D.E., 1962. The brief psychiatric rating scale. Psychol. Rep. 10, 799-812.

Penfield, W., Perot, P., 1963. The brain's record of auditory and visual experience: a final summary and discussion. Brain 86, 596-695.

Robins, L.N., Wing, J., Wittchen, H.U., Helzer, J.E., Babor, T.F., Burke, J., Farmer, A., Jablenski, A., Pickens, R., Regier, D.A., Sartorius, N., Towle, L.H., 1988. The Composite International Diagnostic Interview. Arch. Gen. Psychiatry 45, 1069-1077.

Salisbury, D.F., Shenton, M.E., Sherwood, A.R., Fischer, I.A., Yurgelun-Todd, D.A., Tohen, M., McCarley, R.W., 1998. First-episode schizophrenic psychosis differs from firstepisode affective psychosis and controls in P300 amplitude over left temporal lobe. Arch. Gen. Psychiatry 55, 173-180.

Shenton, M.E., Kikinis, R., Jolesz, F.A., Pollak, S.D., LeMay, M., Wible, C.G., Hokama, H., Martin, J., Metcalf, D., Coleman, M., McCarley, R.W., 1992. Abnormalities of the left temporal lobe and thought disorder in schizophrenia. N. Engl. J. Med. 327, 604-612.

Tranel, D., 1992. Functional neuroanatomy: neuropsycho- logical correlates of cortical and subcortical damage. In: Yudofsky, S.C., Hales, R.E. (Eds.), Neuropsychiatry. American Psychiatric Press, Washington DC, pp. 57-88.

Van Praag, H.M., 1993. Make-Believes in Psychiatry or the Perils of Progress. Brunner Mazel, New York.

Van Praag, H.M., 1997. Over the mainstream: diagnostic requirements for biological psychiatric research. Psychiatry Res. 72, 201-212.

Watson, C., Andermann, F., Gloor, P., Jones-Gotman, M., Peters, T., Evans, A., Olivier, A., Melanson, D., Leroux, G., 1992. Anatomic basis of amygdaloid and hippocampal volume measurement by magnetic resonance imaging. Neurology 42, 1743-1750.

Weinberger, D.R., Berman, K.F., Suddath, R., Torrey, E.F., 1992. Evidence of dysfunction of a prefrontal-limbic network in schizophrenia: a magnetic resonance and regional cerebral blood flow study of discordant monozygotic twins. Am. J. Psychiatry 149, 890-897.

Wood, C.C., McCarthey, G., 1985. A possible frontal lobe contribution to scalp P300. Neurosci. Abstr. 11, 879

Young, A.H., Blackwood, D.H.R., Roxborough, H., McQueen, J.K., Martin, M.J., Kean, D., 1991. A magnetic resonance imaging study of schizophrenia: brain structure and clinical symptoms. Br. J. Psychiatry 158, 158-164.

Zipursky, R.B., Lim, K.O., Sullivan, E.V., Brown, B.W., Pfefferbaum, A., 1992. Widespread cerebral gray matter volume deficits in schizophrenia. Arch. Gen. Psychiatry 49, 195-205.

Zipursky, R.B., Marsh, L., Lim, K.O., DeMent, S., Shear, P.K., Sullivan, E.V., Murphy, G.M., Csernansky, J.G., Pfefferbaum, A., 1994. Volumetric MRI assessment of temporal lobe structures in schizophrenia. Biol. Psychiatry 35, $501-516$. 